\title{
Perineurioma esclerosante: relato de caso e revisão da literatura*
}

\author{
Sclerosing perineurioma: case report and literature review
}

\author{
Thiago Jeunon de Sousa Vargas ${ }^{1}$ \\ Ana Luisa Sobral Bittencourt Sampaio ${ }^{3}$ \\ Geoffrey J. Gottlieb
}

\author{
Maria Auxiliadora Jeunon Sousa ${ }^{2}$ \\ José Dib Mourad ${ }^{4}$
}

\begin{abstract}
Resumo: O perineurioma esclerosante é uma neoplasia benigna rara, constituída exclusivamente por células com diferenciação perineural, dispersas em meio a estroma fibroso denso. Acomete preferencialmente a pele dos quirodáctilos e das regiões palmares e se apresenta como pápula ou nódulo firme, normocrômico e assintomático. Apresentamos um caso de perineurioma esclerosante localizado na região palmar esquerda de uma paciente feminina de 16 anos de idade, com detalhada demonstração dos aspectos clínicos, histopatologia e revisão da literatura publicada em língua inglesa.

Palavras-chave: classificação; dermatologia; diagnóstico; neoplasias da bainha neural; patologia
\end{abstract}

\begin{abstract}
Sclerosing perineurioma is a rare benign neoplasm composed exclusively of perineural differentiation cells spread in a dense fibrous stroma. It affects primarily the skin of fingers and that of the palm of the hands. It appears as a hard papule or nodule, normochromic and asymptomatic. A case of sclerosing perineurioma in the left palm of a 16-year-old female is described, with detailed demonstration of clinical aspects, histopathology and literature review published in the English language. Keywords: classification; dermatology; diagnosis; nerve sheath neoplasms; pathology
\end{abstract}

\section{INTRODUÇÃO}

O perineurioma esclerosante é uma neoplasia benigna rara, pouco conhecida por dermatologistas, anatomopatologistas e dermatopatologistas, que acomete, preferencialmente, a pele dos quirodáctilos e das regiões palmares. Apresenta morfologia bastante característica, tanto do ponto de vista clínico quanto histopatológico, e pode ser diagnosticado com relativa facilidade por médicos que estejam familiarizados com essa doença. O que se segue é a demonstração de um caso e a revisão da literatura de língua inglesa.

\section{RELATO DO CASO}

Paciente feminina, com 16 anos de idade. Apresentou-se para consulta devido a nódulo assintomático, firme, da cor da pele, medindo $1,5 \mathrm{~cm} \mathrm{x}$ $1,0 \mathrm{~cm}$, localizado na região palmar esquerda, próximo à base do terceiro quirodáctilo, surgido há cinco anos (Figura 1). A lesão foi submetida a biópsia excisional e enviada para exame histopatológico. Nos cortes corados pela hematoxilina e eosina (HE), observou-se neoplasia simétrica, bem circunscrita, não encapsulada, orientada verticalmente, com estroma

Recebido em 21.7.2009.

Aprovado pelo Conselho Editorial e aceito para publicação em 31.7.09.

* Trabalho realizado no laboratório de dermatopatologia ID - Investigação em Dermatologia S/C Ltda. - Rio de Janeiro (RJ), Brasil e na Ackerman Academy of Dermatopathology, New York (NY), USA.

Conflito de interesse: Nenhum / Conflict of interest: None

Suporte financeiro: Nenhum / Financial funding: None

Especialista em Dermatologia pela Sociedade Brasileira de Dermatologia (SBD), médico e preceptor do Serviço de Dermatologia do Hospital Geral de Bonsucesso, médico do Laboratório ID - Investigação em Dermatologia S/C Ltda. - Rio de Janeiro (RJ), Brasil.

Especialista em Dermatologia pela Sociedade Brasileira de Dermatologia (SBD), diretora do Laboratório ID - Investigação em Dermatologia S/C Ltda. e professora auxiliar aposentada do Serviço de Dermatologia da Faculdade de Ciências Médicas da Universidade do Estado do Rio de Janeiro - Rio de Janeiro (RJ), Brasil.

3 Especialista em Dermatologia pela Sociedade Brasileira de Dermatologia (SBD), mestranda do Serviço de Dermatologia do Hospital Universitário Clementino Fraga Filho/Universidade Federal do Rio de Janeiro e médica do Laboratório ID - Investigação em Dermatologia S/C Ltda. - Rio de Janeiro (RJ), Brasil.

Membro da Sociedade Brasileira de Cirurgia Dermatológica, mestre e doutor em Cirurgia pela Faculdade de Medicina da Universidade Federal do Rio de Janeiro, professor adjunto aposentado do Departamento de Cirurgia-Geral da Faculdade de Ciências Médicas da Universidade do Estado do Rio de Janeiro Rio de Janeiro (RJ), Brasil.

5 Detentor de certificado pelo American Board of Medical Specialties (Estados Unidos da América) em Dermatopatologia e Anatomia Patológica, diretor da Ackerman Academy of Dermatopathology, New York (NY), USA.

(C)2009 by Anais Brasileiros de Dermatologia 
colagenoso denso (Figuras 2 e 3). Em meio aos feixes colágenos, havia células que variavam em forma algumas arredondadas, com citoplasma facilmente discernível (Figura 4), outras, fusiformes e onduladas (Figura 5). Não se observou pleomorfismo, hipercromasia ou figuras de mitose. Filetes nervosos de permeio foram vistos em meio ao estroma, alguns dos quais em contato direto com as células neoplásicas (Figura 6). Também se identificou áreas com baixa densidade celular e proeminente hialinização do estroma, nas quais predominavam vasos sanguíneos alongados, de paredes conjuntivas finas (Figura 7). $\mathrm{O}$ diagnóstico de perineurioma esclerosante foi sugerido pela morfologia da lesão e confirmado por estudo imuno-histoquímico, que mostrou positividade em padrão citoplasmático para antígeno de membrana epitelial (EMA) e negatividade para proteína S-100 (Figura 8).

\section{DISCUSSÃO}

\section{Troncos nervosos e fascículos nervosos}

Os troncos nervosos são compostos por axônios, células de Schwann e três estruturas de sustentação conhecidas como endoneuro, perineuro e epineuro (Figuras 9 e 10).

O endoneuro é composto por fibras colágenas muito delicadas, inconspícuas à microscopia óptica, mas discerníveis à microscopia eletrônica, que circundam cada conjunto de axônio e células de Schwann.

Os axônios, células de Schwann e endoneuro formam os fascículos nervosos que, por sua vez, são circundados por uma estrutura lamelar conhecida como perineuro. Este é representado por uma a seis fileiras de células achatadas (células perineurais) e quantidades variáveis de tecido conjuntivo que se interpõe por entre essas camadas. $O$ perineuro fun-

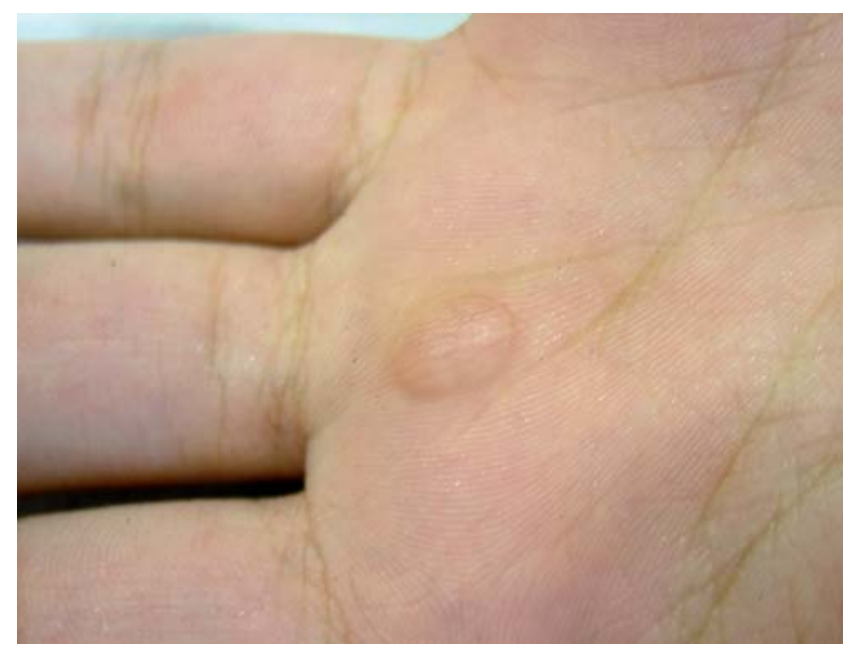

Figura 1: Nódulo normocrômico, de limites bem definidos, medindo $1,5 \mathrm{~cm} \times 1,0 \mathrm{~cm}$, localizado na região palmar esquerda ciona como proteção mecânica e barreira hematonervosa individualizada para cada um dos fascículos nervosos.

O componente externo dos troncos nervosos é o epineuro, um tecido fibroso denso e ricamente vascularizado, responsável por manter os fascículos nervosos próximos uns dos outros. Nas raízes nervosas da coluna espinhal, as células perineurais estão em continuidade com a membrana pioaracnoide do sistema nervoso central, o mesmo ocorrendo com o epineuro em relação com a dura-máter. ${ }^{1} \mathrm{Na}$ pele, não há troncos nervosos propriamente ditos, apenas fascículos nervosos isolados, de forma que o perineuro se encontra em contato direto com a derme.

\section{Histórico e definição de perineurioma}

O perineurioma foi descrito pela primeira vez em 1978. ${ }^{2}$ Lazarus e Trombetta relataram os achados

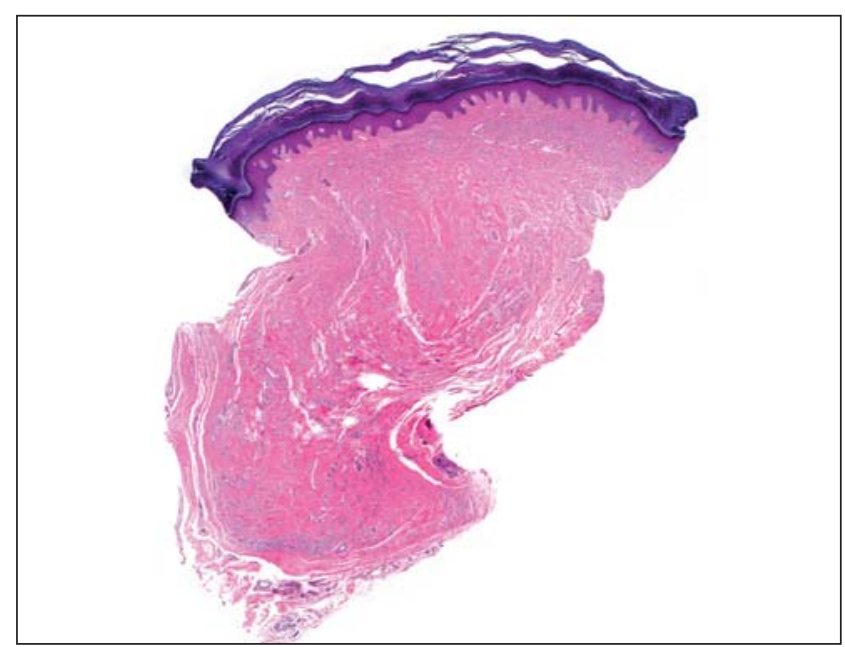

FigurA 2: Neoplasia simétrica, bem circunscrita, orientada verticalmente, exibindo estroma colagenoso denso (HE, 20x)

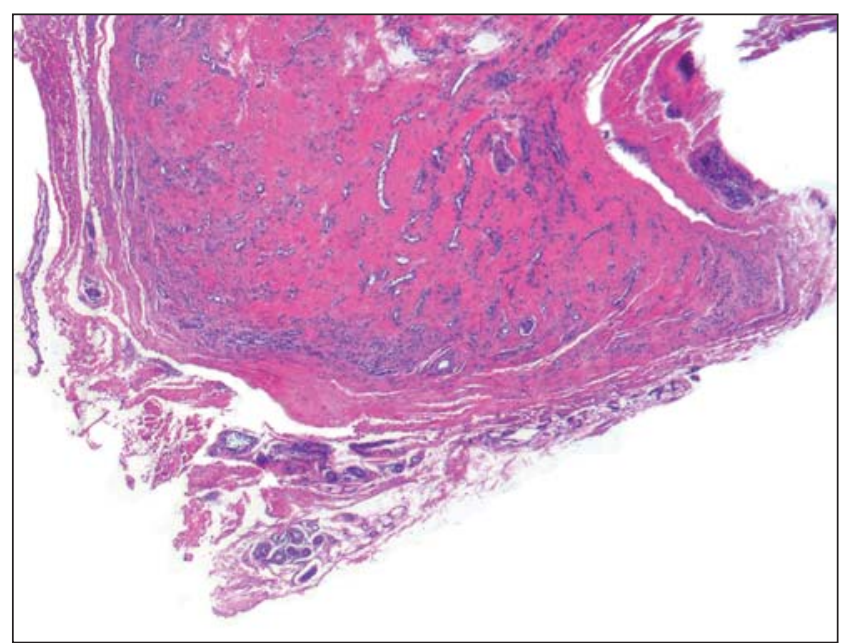

Figura 3: Base do fragmento demonstrando a boa circunscrição desta neoplasia não encapsulada ( $\mathrm{HE}, 40 \mathrm{x})$ 


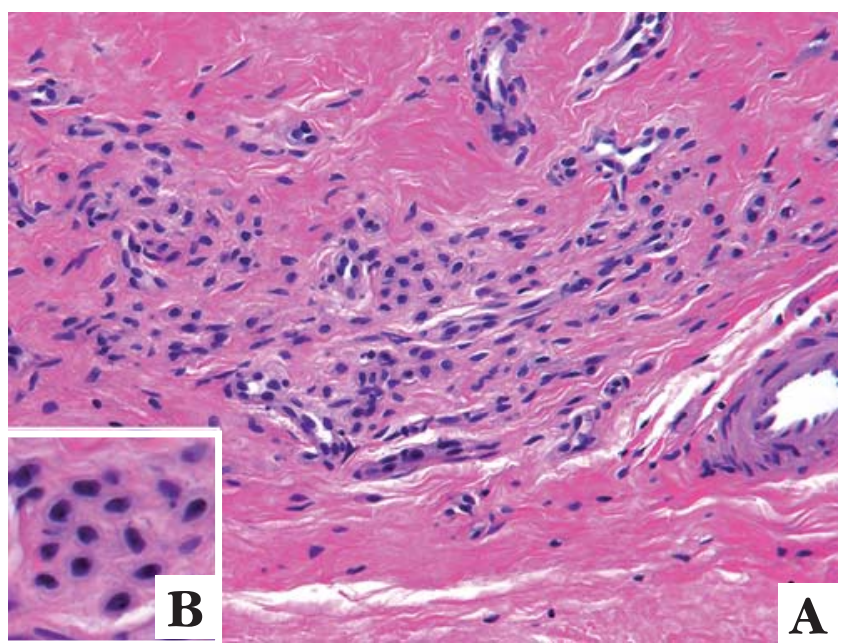

Figura 4: A - Células arredondadas, de citoplasma evidente e núcleos uniformes, arranjadas em unidades individuais ou pequenos grupamentos, em meio a estroma esclerótico (HE, 100x) B - Detalhe das células arredondadas em maior aumento (HE, 400x)

de uma neoplasia de parte mole excisada do músculo gastrocnêmio de um homem de 45 anos, que foi originalmente diagnosticado como neurofibroma nos cortes corados pela hematoxilina e eosina. Por meio de estudos ultraestruturais, os autores provaram que essa neoplasia consistia em um perineurioma e definiram critérios de diferenciação perineural aplicáveis às células normais e às patológicas. À microscopia eletrônica, as células perineurais exibem formatos fusiformes, processos citoplasmáticos longos e finos, tight junctions bem formadas, lâmina externa incompleta e um citoplasma granuloso característico, repleto de vesículas picnóticas, mas com poucas mitocôndrias e pequenas quantidades de retículo endoplasmático.

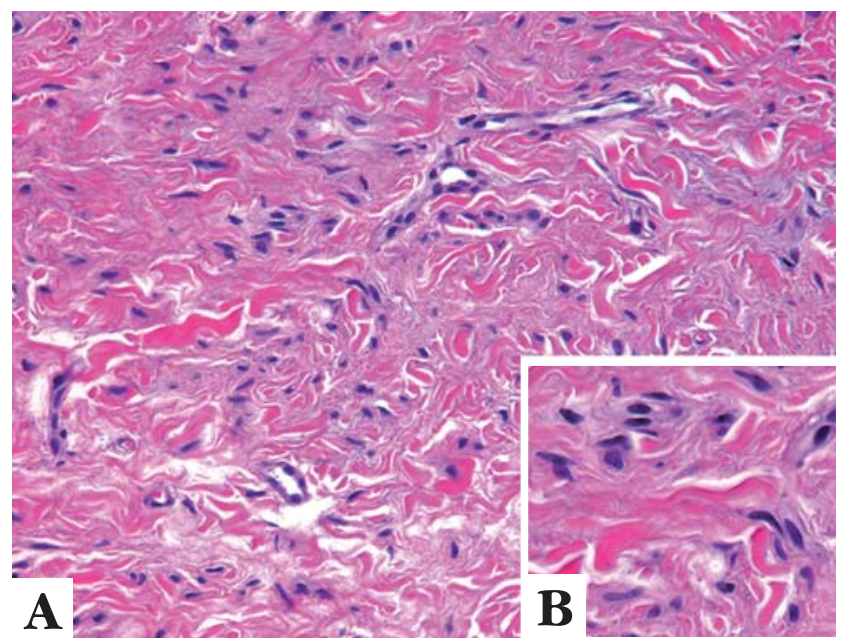

Figura 5: A - Células fusiformes de núcleos alongados, algumas das quais de formato sinuoso, em meio a estroma fibroso denso (HE, 100x). B - Detalhe das células fusiformes em maior aumento (HE, 400x)

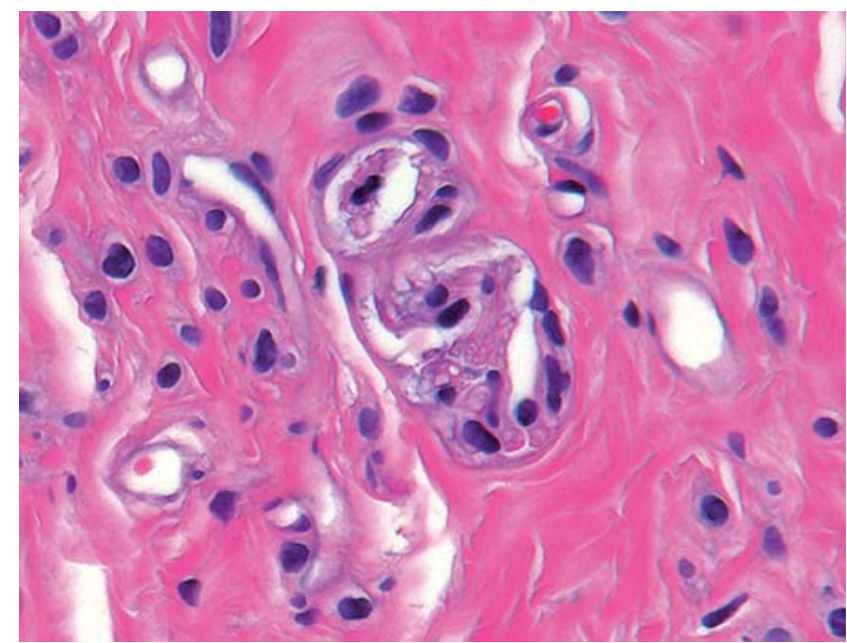

Figura 6: Células arredondadas ao redor de um filete nervoso preexistente, algumas das quais em contato direto com o perineuro (HE, 400x)

Alguns anos mais tarde, demonstrou-se que as células perineurais são positivas para EMA e negativas para proteína S-100 em estudos imuno-histoquímicos, dispensando a necessidade de microscopia eletrônica para confirmação de casos na prática diária. ${ }^{3.5}$ Outros antígenos frequentemente expressos por essas células são Glut-1, claudina-1, colágeno IV e laminina. Embora nenhum desses antígenos seja absolutamente específico, eles são considerados "marcadores" de diferenciação perineural em um contexto morfológico apropriado.

Os perineuriomas são um grupo raro de neoplasias benignas da bainha do nervo compostas, exclusivamente, por células com diferenciação peri-

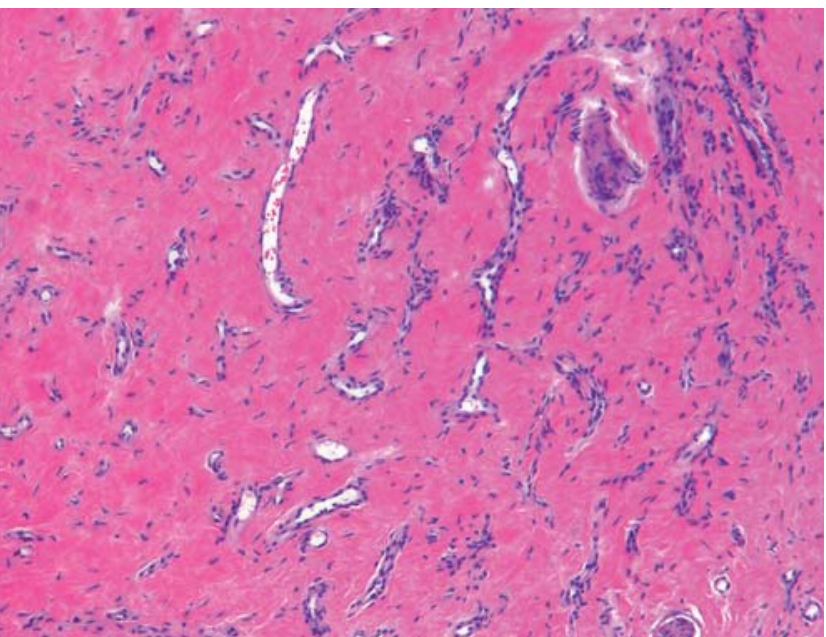

Figura 7: Área de baixa densidade celular, exibindo estroma intensamente esclerótico e grande número de vasos alongados de parede conjuntiva fina (HE, 100x) 


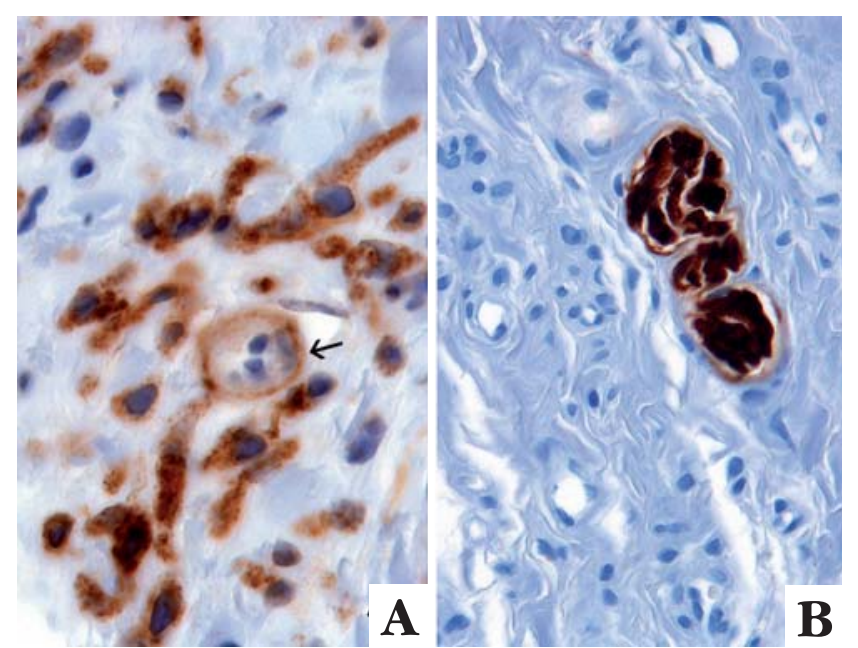

Figura 8: A - Imuno-histoquímica para EMA exibindo positividade de padrão citoplasmático das células neoplásicas e do perineuro de um filete nervoso preexistente (seta) (imunoperoxidase para EMA, 400x). B - Imuno-histoquímica para proteína S-100 exibindo negatividade das células neoplásicas e positividade de um filete nervoso preexistente (imunoperoxidase para proteína S-100, 100x)

neural, em contraste com os schwanomas, formados, unicamente, por células de Schwann, e com os neurofibromas, que apresentam axônios e uma mistura de tipos celulares que incluem células de Schwann, fibroblastos e células semelhantes às que compõem o perineuro. ${ }^{6}$ Lenahan e Gottlieb relataram um tumor com dois componentes distintos, um dos quais exibia aspectos morfológicos e imunoistoquímicos de neurofibroma, enquanto o outro, de perineurioma. Os autores descreveram essa lesão como "neoplasia neural benigna com características de neurofibroma e perineurioma". ' Perineuriomas não apresentam associação com neurofibromatose.

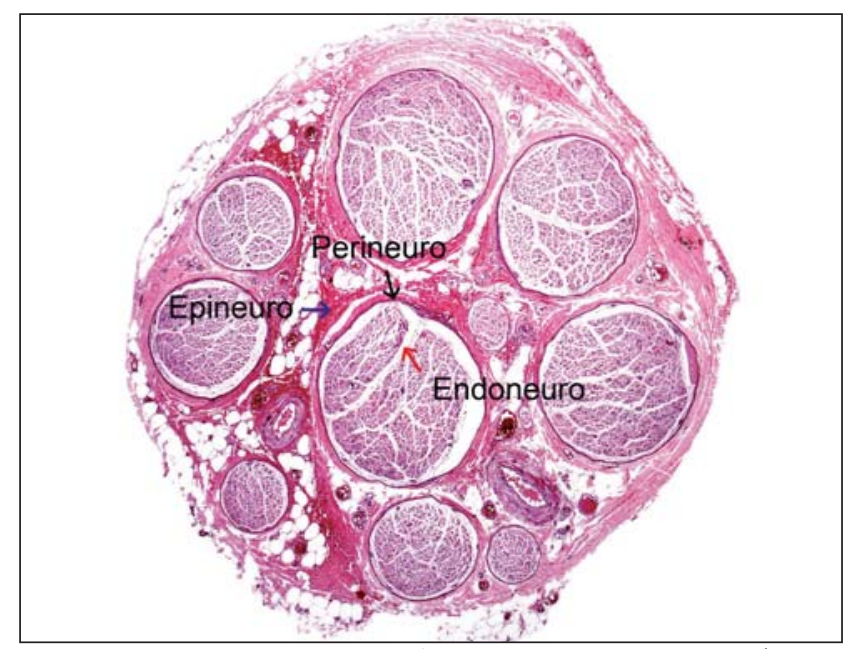

Figura 9: Cortes transversais de um tronco nervoso (HE, 40x) (seta azul = epineuro; seta preta $=$ perineuro; seta vermelha = endoneuro)"

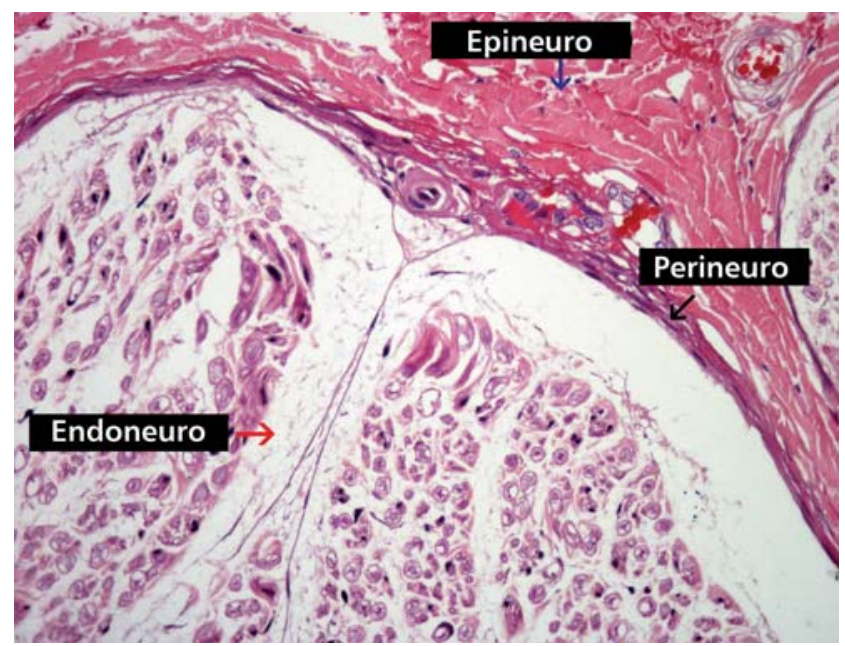

Figura 10: Cortes transversais de um tronco nervoso (HE, 400x) (seta azul $=$ epineuro; seta preta $=$ perineuro; seta vermelha $=$ endoneuro)

\section{Classificação}

Existem três categorias principais que compõem o grupo de neoplasias genericamente conhecidas como perineuriomas: perineurioma intraneural, perineurioma de partes moles e perineurioma esclerosante. Todos eles compartilham o perfil imuno-histoquímico e ultraestrutural, mas são distinguidos por meio das particularidades nas apresentações clínicas e histopatológicas.

\section{Perineurioma intraneural (PI)}

O perineurioma intraneural (PI) foi considerado uma neuropatia degenerativa e designado no passado como neuropatia localizada hipertrófica, mononeuropatia hipertrófica ou neurofibrose localizada hipertrófica, até que Emory et al. demonstraram que se tratava, na realidade, de uma neoplasia. ${ }^{8}$ Tipicamente, uma proliferação de células perineurais de formato fusiforme ocorre no corpo de um tronco nervoso e se dispõe em redemoinhos concêntricos ao redor de axônios e células de Schwann preexistentes e comprimidos. Esse padrão é observado mais facilmente nos cortes transversais. A apresentação clínica estereotípica é de um paciente abaixo dos 30 anos de idade com espessamento segmentar e disfunção de um tronco nervoso periférico de uma extremidade.

\section{Perineurioma de partes moles (PPM)}

O perineurioma de partes moles (PPM) tem seu pico de incidência na meia-idade e ocorre mais frequentemente no tecido subcutâneo das extremidades, 
TABELA 1: Informações resumidas dos casos de perineurioma esclerosante previamente publicados

\begin{tabular}{|c|c|c|c|c|c|c|}
\hline $\begin{array}{l}\text { Número } \\
\text { do caso }\end{array}$ & $\begin{array}{l}\text { Idade } \\
\text { (anos) }\end{array}$ & Sexo & Local & $\begin{array}{l}\text { Tamanho§ } \\
(\mathbf{c m})\end{array}$ & Duração & Referência \\
\hline 1 & 25 & M & Primeiro quirodáctilo esquerdo & 1,1 & 3 anos & {$[13]$} \\
\hline 2 & 55 & M & Primeiro quirodáctilo esquerdo & 1,8 & 40 anos & {$[13]$} \\
\hline 3 & 30 & $\mathrm{~F}$ & Primeiro quirodáctilo direito & 1,5 & Muitos anos & {$[13]$} \\
\hline 4 & 27 & M & Primeiro quirodáctilo direito & 1,5 (estimado) & Anos & {$[13]$} \\
\hline 5 & 23 & M & Primeiro quirodáctilo direito & 1,0 & - & {$[13]$} \\
\hline 6 & 33 & M & Primeiro quirodáctilo direito & 1,5 & Vários anos & {$[13]$} \\
\hline 7 & 29 & $\mathrm{~F}$ & Segundo quirodáctilo direito & 0,7 & - & {$[13]$} \\
\hline 8 & 29 & M & Segundo quirodáctilo direito & 1,2 & 1 ano & {$[13]$} \\
\hline 9 & - & M & Segundo quirodáctilo direito & 2,5 & 6 meses & {$[13]$} \\
\hline 10 & 9 & $\mathrm{~F}$ & Terceiro quirodáctilo esquerdo & 1,2 & Anos & {$[13]$} \\
\hline 11 & 21 & M & Terceiro quirodáctilo esquerdo & 1,3 & Muitos anos & {$[13]$} \\
\hline 12 & 24 & M & Terceiro quirodáctilo direito & 1,0 & 6 anos & {$[13]$} \\
\hline 13 & 22 & $\mathrm{~F}$ & Terceiro quirodáctilo direito & 2,0 & Muitos anos & {$[13]$} \\
\hline 14 & 30 & M & Quarto quirodáctilo esquerdo & 3,3 & 2 anos & {$[13]$} \\
\hline 15 & 22 & M & Quarto quirodáctilo esquerdo & 2,7 & - & {$[13]$} \\
\hline 16 & 22 & $\mathrm{~F}$ & Quarto quirodáctilo direito & 0,8 & - & {$[13]$} \\
\hline 17 & 24 & M & Quarto quirodáctilo direito & 0,7 & - & {$[13]$} \\
\hline 18 & 25 & M & Palma direita & 1,8 & 4 anos & {$[13]$} \\
\hline 19 & 11 & M & Palma direita & 0,9 & - & {$[13]$} \\
\hline 20 & 67 & $\mathrm{~F}$ & Quirodáctilo (não especificado) & 0,5 & - & {$[14]^{*}$} \\
\hline 21 & 21 & $\mathrm{~F}$ & Terceiro quirodáctilo esquerdo & 1,0 & - & {$[15]$} \\
\hline $22+$ & 16 & M & $\begin{array}{l}\text { Palma direita, segundo } \\
\text { quirodáctilo esquerdo }\end{array}$ & 2,5 e 1,0 & $\begin{array}{l}2 \text { anos e } \\
5 \text { meses }\end{array}$ & {$[16]$} \\
\hline 23 & 14 & M & Primeiro quirodáctilo esquerdo & 1,8 & - & {$[17]^{*}$} \\
\hline 24 & 16 & M & Segundo quirodáctilo direito & 1,0 & - & {$[17]^{*}$} \\
\hline 25 & 11 & $\mathrm{~F}$ & Palma esquerda & 2,8 & - & {$[18]$} \\
\hline 26 & 30 & M & Primeiro quirodáctilo direito & 3,0 & - & {$[18]$} \\
\hline 27 & 16 & M & Quarto quirodáctilo esquerdo & 4,0 & - & {$[18]$} \\
\hline 28 & 25 & M & Terceiro quirodáctilo direito & 1,2 & - & {$[18]$} \\
\hline 29 & 49 & M & Primeiro quirodáctilo esquerdo & 1,7 & - & {$[18]$} \\
\hline 30 & 9 & M & Terceiro quirodáctilo esquerdo & 1,0 & Vários meses & [19] \\
\hline 31 & 18 & $\mathrm{~F}$ & Terceiro quirodáctilo esquerdo & 0,7 & Vários meses & [19] \\
\hline 32 & 36 & $\mathrm{~F}$ & Axila esquerda & 8,0 & 10 meses & {$[20]$} \\
\hline 33 & 42 & $\mathrm{~F}$ & Quirodáctilo (não especificado) & 1,5 & - & {$[21]^{*}$} \\
\hline 34 & 58 & $\mathrm{~F}$ & Pé (não especificado) & 4 & - & {$[21]^{*}$} \\
\hline 35 & 47 & $\mathrm{~F}$ & Palma (não especificada) & 3 & - & {$[21]^{*}$} \\
\hline 36 & 7 & M & Segundo quirodáctilo esquerdo & 1,0 & - & {$[22]^{*}$} \\
\hline 37 & 15 & $\mathrm{~F}$ & Segundo quirodáctilo direito & 0,7 & - & {$[22]^{*}$} \\
\hline 38 & 11 & $\mathrm{~F}$ & Segundo quirodáctilo direito & 1,0 & 5 anos & {$[23]$} \\
\hline 39 & 11 & $\mathrm{~F}$ & Palma esquerda & 2,8 & 1 ano & [24] \\
\hline 40 & 16 & M & Quarto quirodáctilo esquerdo & 4,0 & - & {$[24]$} \\
\hline 41 & 39 & $\mathrm{~F}$ & $\begin{array}{l}\text { Segundo quirodáctilo } \\
\text { (não especificado) }\end{array}$ & 1,1 & 1 ano e 1 mês & {$[25]$} \\
\hline $42+$ & 21 & $\mathrm{~F}$ & Mãos e antebraços bilateralmente & $0,3-0,6$ & 10 anos & {$[26]$} \\
\hline
\end{tabular}

$\mathrm{M}=$ masculino $; \mathrm{F}=$ feminino $; \mathrm{cm}=$ centímetros

*Outros tipos de perineurioma incluídos na mesma série

+ Mais de uma lesão de perineurioma esclerosante no mesmo paciente

- Informação não disponível

$\S$ Medida da maior dimensão da lesão 
da cintura escapular ou pélvica e do tronco. No entanto, aproximadamente $30 \%$ dos casos envolvem partes moles mais profundas, incluindo alguns localizados na cavidade peritoneal, enquanto casos raros são de localização dérmica. O tamanho tumoral é variável, indo de poucos milímetros a vários centímetros. PPMs são compostos por células fusiformes com prolongamentos citoplasmáticos longos, finos e delicados e apresentam grande variabilidade de padrões arquiteturais, dentre eles estoriforme, fascicular, reticular, plexiforme, infiltrativo e mixoide. ${ }^{6,9,10}$ Zelger sugere a hipótese de que alguns dos casos relatados como tumor mixoide da bainha do nervo (mixoma da bainha do nervo) são, na realidade, perineuriomas. ${ }^{11}$ Curiosamente, um caso de perineurioma parcialmente composto por células granulares foi relatado, sendo que todas as células dessa neoplasia foram positivas para EMA, Glut-1 e claudina-1, independentemente da morfologia (células granulares ou não) ${ }^{12}$

\section{Perineurioma esclerosante (PE)}

$\mathrm{O}$ perineurioma esclerosante (PE) foi descrito pela primeira vez em 1997 por Fetsch e Miettinen em uma série de 19 pacientes. ${ }^{13}$ Em pesquisa realizada no banco de dados Medline/Pubmed, identificamos outros 23 casos na literatura de língua inglesa e nenhum na língua portuguesa. ${ }^{14-26} \mathrm{~A}$ tabela 1 resume as informações clínicas de todos esses casos. A ausência de um único diagnóstico clínico correto ou mesmo da inclusão do PE em uma lista de diagnósticos diferenciais em todos os casos previamente relatados evidencia que os dermatologistas não estão familiarizados com essa neoplasia.

O PE se apresenta como pápula, nódulo ou pequeno tumor indolor, da cor da pele, medindo de $0,3 \mathrm{~cm}$ a $8,0 \mathrm{~cm}$ (média $=2,7 \mathrm{~cm} ;$ mediana $=2,9 \mathrm{~cm}$ ) na maior dimensão e com grande predileção pelos quirodáctilos e palmas. Ele afeta quase igualmente homens e mulheres (relação $\mathrm{H}: \mathrm{M}=1,3$ ) e ocorre em indivíduos entre sete e 67 anos de idade (média $=25,7$ anos; mediana $=23$ anos). As lesões, em geral, são solitárias, mas um paciente com duas lesões (palma direita e segundo quirodáctilo esquerdo) e outro com múltiplas (mãos e antebraços) foram relatados. ${ }^{16,26}$

Histopatologicamente, o PE mostra a silhueta de uma neoplasia benigna, é orientado verticalmente, é relativamente simétrico e bem circunscrito, embora não encapsulado. O estroma é densamente esclerótico e as células apresentam dois formatos distintos, ambos comumente presentes em uma mesma lesão.
Um deles é fusiforme e ondulado, às vezes associado a processos citoplasmáticos finos; o outro é arredondado e de aparência epitelióide, com citoplasma evidente. Os núcleos, geralmente, são pequenos, com cromatina densa e nucléolo indistinto. Figuras de mitose são raras ou ausentes e não há pleomorfismo nuclear. Em decorrência da grande quantidade de colágeno, o PE não aparenta ser densamente celular quando observado em pequeno aumento. As células se dispõem por entre os feixes colágenos e se arranjam em unidades individuais, em pequenos ninhos, em "fila indiana" e em redemoinhos. Em algumas lesões, vasos sanguíneos dilatados de paredes finas e fascículos nervosos estão presentes em meio à neoplasia. Chamamos a atenção para algumas células neoplásicas dispostas bastante próximas e às vezes tocando o perineuro dos filetes nervosos preexistentes, uma observação que não foi salientada nas publicações prévias e que pode dar a dica para o diagnóstico. Alguns mastócitos de permeio são frequentemente encontrados. Recentemente, um componente adipocítico foi relatado em um caso isolado que, no restante, apresentava todas as características típicas de um perineurioma esclerosante. ${ }^{25}$

Dois casos em 1998 e outros seis em 2001 foram relatados com a nomenclatura de "perineurioma fibroso cutâneo". De acordo com a análise das fotomicrografias publicadas, esses casos teriam sido interpretados por nós como perineuriomas esclerosantes. ${ }^{27,28}$ No entanto, não foram incluídos na presente revisão em respeito às opiniões divergentes dos autores.

Em contraste com os PPMs, o PE exibe um padrão morfológico muito mais constante, como pode ser observado pela análise das publicações prévias sobre essa neoplasia. Embora seja sempre importante recordar os diagnósticos diferenciais frequentemente citados para essa lesão, entre os quais, fibroma esclerótico, dermatofibroma, angiofibroma, fibroma da bainha do tendão, tumor tenossinovial fibrosante de células gigantes, tricodiscoma, neurofibroma, tumor glômico, sarcoma epitelioide e meningioma, nenhum deles é uma consideração real na maioria dos casos de perineurioma esclerosante. Se determinado dermatopatologista estiver familiarizado com os aspectos morfológicos dessa lesão, o diagnóstico correto poderá ser fortemente sugerido e estudos imunohistoquímicos e/ou ultraestruturais deverão ser realizados para confirmação.

\section{AGRADECIMENTOS:}

Os autores se sentem endividados com o doutor Mario Lucio Cordeiro Araujo Jr., que gentilmente cedeu cortes histológicos de troncos nervosos para a confecção das Figuras 9 e 10. 


\section{REFERÊNCIAS}

1 Piña-Oviedo S, Ortiz-Hidalgo $C$. The normal and neoplastic perineurium: a review. Adv Anat Pathol. 2008; 15:147-64.

2 Lazarus SS, Trombetta LD. Ultrastructural identification of a benign perineurial cell tumor. Cancer. 1978;41:1823-829.

3 Pinkus GS, Kurtin PJ. Epithelial membrane antigen: a diagnostic discriminant in surgical pathology. Immunohistochemical profile in epithelial, mesenchymal, and hematopoietic neoplasms using paraffin sections and monoclonal antibodies. Hum Pathol. 1985; 16:929-40.

4 Ariza A, Bilbao JM, Rosai J. Immunohistochemical detection of epithelial membrane antigen in normal perineurial cells and perineurioma. Am J Surg Pathol. 1988;12:678-83.

5 Theaker JM, Fletcher CDM. Epithelial membrane antigen expression by the perineurial cell: further studies of peripheral nerve lesions. Histopathology. 1989; 14:581-92.

6 Hornick JL, Fletcher CD. Soft tissue perineurioma: clinicopathologic analysis of 81 cases including those with atypical histologic features. Am J Surg Pathol. 2005;29:845-58.

7 Lenahan S, Gottlieb GJ. New quandary: perineurioma? Dermatopathol: Pract \& Conc 2004;10:3. Available at: http://www.derm101.com

8 Emory TS, Scheithauer BW, Hirose T, Wood M, Onofrio $\mathrm{BM}$, Jenkins RB. Intraneural perineurioma a clonal neoplasm associated with abnormalities of chromosome 22. Am J Surg Pathol. 1995;103:696-704.

9 Mentzel T, Kutzner H. Reticular and plexiform perineurioma: clinicopathological and immunohistochemical analysis of two cases and review of perineurial neoplasms of skin and soft tissues. Virchows Arch. 2005; 447:677-82.

10 Graadt von Roggen JF, McMenamin ME, Belchis DA, Rosenberg AE, Fletcher CDM. Reticular perineurioma a distinctive variant of soft tissue perineurioma. Am J Surg Pathol. 2001;25:485-93.

11 Zelger, B. Clue to diagnosis. Dermatopathol: Pract \& Conc 2000;6. Available at www.derm101.com.

12 Al-Daraji WI. Granular perineurioma: the first report of a rare distinctive subtype of perineurioma. Am J Dermatopathol. 2008;30:163-8.

13 Fetsch JF, Miettinen M. Sclerosing perineurioma a clinicopathologic study of 19 cases of a distinctive soft tissue lesion with a predilection for the fingers and palms of young adults. Am J Surg Pathol. 1997;21:1433-442.

14 Robson AM, Calonje E. Cutaneous perineurioma: a poorly recognized tumour often misdiagnosed as epithelioid histiocytoma. Histopathology. 2000;37:332-9.

15 Burgues $\mathrm{O}$, Monteagudo $\mathrm{C}$, Noguera R, Revert A, MolinaI, Llombart-Bosch A. Cutaneous sclerosing Pacinian-like perineurioma. Histopathology. 2001; 39:498-502.

16 Huang HY, Sung MT. Sclerosing perineuriomas affecting bilateral hands. Br J Dermatol. 2002; 146:129-33.

17 Balarezo FS, Muller RC, Weiss RG, Brown T, Knibbs D, Joshi VV. Soft tissue perineuriomas in children: report of three cases and review of the literature [corrected]. Pediatr Dev Pathol. 2003;6:137-41.

18 Yamaguchi U, Hasegawa T, Hirose T, Fugo K, Mitsuhashi T, Shimizu M et al. Sclerosing perineurioma: a clinico- pathological study of five cases and diagnos-

tic utility

of immunohistochemical staining for GLUT1. Virchows Arch. 2003;443:159-63.

19 Canales-Ibarra C, Magariños G, Olsoff-Pagovich P, OrtizHidalgo C. Cutaneous sclerosing perineurioma of the digits: an uncommon soft-tissue neoplasm. Report of two cases with immunohistochemical analysis. J Cutan Pathol. 2003;30:577-81.

20 Lee LH, Bos GD, Marsh WL Jr, Wakely PE Jr. Fineneedle aspiration cytology of sclerosing perineurioma. Ann Diagn Pathol. 2004;8:80-6.

21 Rankine AJ, Filion PR, Platten MA, Spagnolo DV. Perineurioma: a clinicopathological study of eight cases. Pathology. 2004;36:309-15.

22 Brock JE, Perez-Atayde AR, Kozakewich HP, Richkind KE, Fletcher JA, Vargas SO. Cytogenetic aberrations in perineurioma: variation with subtype. Am J Surg Pathol. 2005;29:1164-9.

23 Nakamura T, Kawamura T, Nariya S, Fujiwara M. Cutaneous sclerosing perineurioma of the digit. Int $\mathrm{J}$ Dermatol. 2006;45:1086-8.

24 Miyake M, Tateishi U, Maeda T, Arai Y, Seki K, Hasegawa $T$ et al. Sclerosing perineurioma: tumor of the hand with a short T2. Skeletal Radiol. 2006;35:543-6.

25 Macarenco AC, Macarenco RS. Cutaneous lipomatous sclerosing perineurioma. Am J Dermatopathol. 2008; 30:291-4.

26 Rubin AI, Yassaee M, Johnson W, Elenitsas R, Zaladonis $\mathrm{J} \mathrm{Jr}$, Seykora JT. Multiple cutaneous sclerosing perineuriomas: an extensive presentation with involvement of the bilateral upper extremities. J Cutan Pathol. 2009;36 Suppl 1:60-5.

27 Smith K, Skelton H. Cutaneous fibrous perineurioma. J Cutan Pathol. 1998;25:333-7.

28 Skelton HG, Williams J, Smith KJ. The clinical and histologic spectrum of cutaneous fibrous perineuriomas. Am J Dermatopathol. 2001;23(3):190-6.

ENDEREÇO PARA CORRESPONDÊNCIA / MAILING ADDRESS:
Thiago Jeunon de SOUsa Vargas
Rua Barão de Mesquita, 200-Ap. 901. Tijuca
20540003 Rio de Janeiro
2122340722
e-mail: thiago.jeunon@gmail.com

ENDEREÇO PARA CORRESPONDÊNCIA / MAILING ADDRESS:

Rua Barão de Mesquita, 200 - Ap. 901. Tijuca 20540003 Rio de Janeiro

e-mail: thiago.jeunon@gmail.com

Como citar este artigo / How to cite this article: Jeunon T, Jeunon-Sousa MA, Sampaio ALSB, Mourad JD, Gottlieb GJ. Perineurioma esclerosante: relato de caso e revisão da literatura. An Bras Dermatol. 2009;84(6):643-9. 